Kompetente Antworten innerhalb von 48 Stunden!
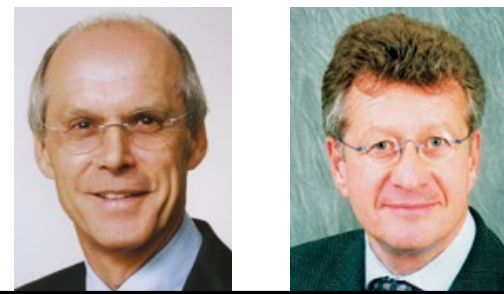

Dr. med. P. Stiefelhagen

Internist,

Hachenburg

\title{
Wie wenig Cholesterin darf's sein?
}

$?$ Frage von Dr. Q. S.: Mein Patient (1,85 m, 103 kg, Blutdruck: 130/95 $\mathrm{mmHg}$ ) nimmt seit fünf Monaten $2 \times$ $10 \mathrm{mg} / \mathrm{d}$ Atorvastatin. Unter dieser Medikation ist sein LDL-Cholesterin-Wert von 140 auf 101 mg/dl gesunken. Sein Nüchternblutzuckerwert liegt bei 120 $\mathrm{mg} / \mathrm{dl}$, sein $\mathrm{HbA}_{1 \mathrm{c}}$-Wert bei 6,3\%.

Er nimmt keine Antidiabetika ein. Seine übrigen Blutwerte sind normal. Nun überlege ich, ob ich die Atorvastatin-Dosis erhöhen sollte. Was wäre ein guter Cholesterin-Zielwert?

MMW-Experte Stiefelhagen: Bei dem Patienten dürfte ein hohes kardiovaskuläres Risiko vorliegen, sodass ein LDL-Cholesterin-Zielwert von unter $100 \mathrm{mg} / \mathrm{dl}$ angestrebt werden sollte. Das wurde mit $20 \mathrm{mg} / \mathrm{d}$ Atorvastatin ja fast erreicht. Wenn der Patient das Statin gut verträgt, spricht nichts dagegen, die Dosis auf $40 \mathrm{mg}$ zu erhöhen. Für das LDLCholesterin gilt: je weniger, umso besser.

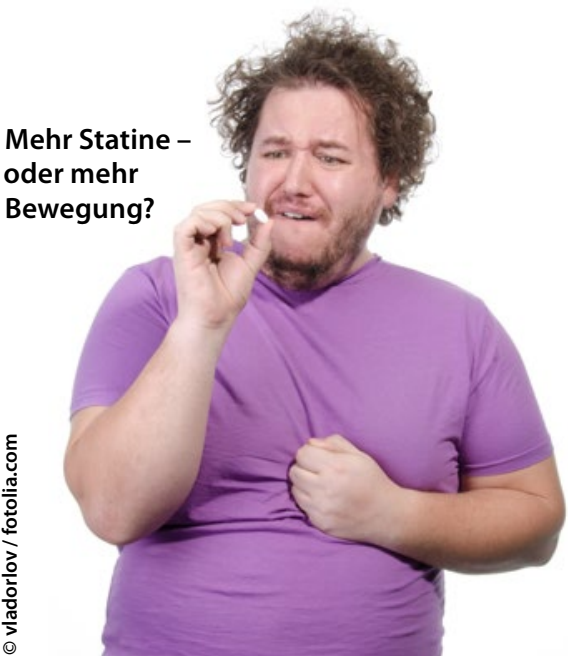

MMW-Experte FüeßI: Leider erfahren wir nicht, wie alt der Patient ist, auch bezüglich der Familienanamnese fehlen die Angaben. Offensichtlich handelt es sich hier um eine Primärprophylaxe einer Arteriosklerose. Der wichtigste Risikofaktor des Patienten ist ein derzeit noch leichter Diabetes mellitus.

Allerdings ist der Patient mit einem BMI von $30,1 \mathrm{~kg} / \mathrm{m}^{2}$ adipös. Viel wichtiger als eine weitere Senkung des LDLCholesterins durch eine Erhöhung der Atorvastatin-Dosis erscheint es mir, den Patienten durch eine Änderung des Lebensstils auf seinem unweigerlichen Weg zu einer Verschlechterung seines Diabetes mellitus aufzuhalten. Das ist unbequem, aber für die Gesundheit des Patienten sinnvoller, als mehr Statine zu schlucken.

\section{Wie oft impft man Frauen gegen Röteln?}

$?$ Anonym gestellte Frage: Eine Mutter will wieder schwanger werden. Vor der ersten Schwangerschaft erhielt sie zweimal eine Röteln- und einmal eine Masern-Mumps-Röteln-Impfung. Im Mutterpass ist aber ein unzureichender Rötelntiter vermerkt.

MMW-Experte FüeßI: Eine Immunisierung ist trotz nicht nachweisba- rer Antikörper gegeben. Möglicherweise reagiert die Patientin mit Antikörpern, die mit den üblichen Messmethoden nicht erfasst werden. Sollte sie Nonresponderin sein, würde auch eine vierte Impfung nichts bringen. Ich würde deshalb davon absehen, selbst wenn wieder ein Kinderwunsch besteht.

Die STIKO empfahl bis zum Jahr 2009, seronegative Frauen mit Kinder- wunsch einmalig gegen Röteln zu impfen und den Erfolg zu kontrollieren. Neuere Daten führten zu einer Änderung: Nun soll zweimal geimpft werden, da dies mit einer soliden Immunität korreliert - und zwar so stark, dass sogar auf die Überprüfung des Serostatus verzichtet werden kann. Wäre man dieser Empfehlung gefolgt, würde sich Ihre Frage nun gar nicht stellen. 